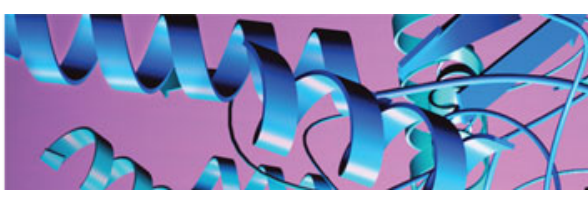

REPORT

\title{
Unraveling amyloid formation paths of Parkinson's disease protein $\alpha$-synuclein triggered by anionic vesicles
}

\author{
Juris Kiskis, Istvan Horvath, Pernilla Wittung-Stafshede* and Sandra Rocha*
}

Department of Biology and Biological Engineering, Chalmers University of Technology, 41296 Gothenburg, Sweden

Quarterly Reviews of Biophysics (2017), 50, e3, page 1 of 9 doi:10.1017/S0033583517000026

Abstract. Amyloid formation of the synaptic brain protein $\alpha$-synuclein $(\alpha S)$ is related to degeneration of dopaminergic neurons in Parkinson's disease patients. $\alpha \mathrm{S}$ is thought to function in vesicle transport and fusion and it binds strongly to negatively charged vesicles in vitro. Here we combined circular dichroism, fluorescence and imaging methods in vitro to characterize the interaction of $\alpha \mathrm{S}$ with negatively charged vesicles of DOPS (1,2-dioleoyl-sn-glycero-3-phospho-L-serine, sodium salt) and DOPG (1,2-dioleoyl-sn-glycero-3phospho-(1'-rac-glycerol), sodium salt) and the consequences of such interactions on $\alpha \mathrm{S}$ amyloid formation. We found that lipid headgroup chemistry modulates $\alpha \mathrm{S}$ interactions and also affects amyloid fiber formation. During the course of the experiments, we made the unexpected discovery that pre-formed $\alpha \mathrm{S}$ oligomers, typically present in a small amount in the $\alpha \mathrm{S}$ starting material, acted as templates for linear growth of anomalous amyloid fibers in the presence of vesicles. At the same time, the remaining $\alpha \mathrm{S}$ monomers were restricted from vesicle-mediated nucleation of amyloid fibers. Although not a dominant process in bulk experiments, this hidden $\alpha \mathrm{S}$ aggregation pathway may be of importance in vivo.

\section{Introduction}

The protein alpha-synuclein $(\alpha \mathrm{S})$ is a major component of amyloid aggregates found in Lewy body inclusions, which are the pathological hallmark of Parkinson's disease (PD). $\mathrm{PD}$ is the second most common neurological disorder and the most common movement disorder. The assembly process of the 140-residue protein $\alpha \mathrm{S}$ into amyloid fibrils, via oligomeric intermediates, has been linked to the molecular basis of PD (Uversky, 2007). Duplications, triplications and point-mutations in the $\alpha \mathrm{S}$ gene are related to familial PD cases (Polymeropoulos et al. 1997; Spillantini et al. 1997).

The exact function of $\alpha \mathrm{S}$ is unknown, but it is suggested that the protein is involved in synaptic vesicle release and trafficking, regulation of enzymes and transporters, and control

* Authors for correspondence: Pernilla Wittung-Stafshede and Sandra Rocha, Department of Biology and Biological Engineering, Chalmers University of Technology, 41296 Gothenburg, Sweden. Email: pernilla. wittung@chalmers.se and sandra.rocha@chalmers.se of the neuronal apoptotic response (Dev et al. 2003; Lassen et al. 2016). $\alpha \mathrm{S}$ is present at presynaptic nerve terminals (Eliezer et al. 2001; Iwai et al. 1995; Maroteaux et al. 1988) and it is reported that the protein exists in vivo in both free cytosolic and membrane-bound states (Lee et al. 2002). Membrane-bound $\alpha \mathrm{S}$ can generate nuclei/oligomers, which can seed the aggregation of cytosolic $\alpha \mathrm{S}$ (Lee et al. 2002). The monomeric $\alpha \mathrm{S}$ form in solution has a disordered structure, whereas the membrane-bound state is rich in alpha-helix structure (Bodner et al. 2009; Davidson et al. 1998; Eliezer et al. 2001; Fusco et al. 2014). PD pathology may be associated with change or disruption of $\alpha$ S-lipid interactions, and in vitro studies have indicated that early-onset PD mutations can affect the binding of $\alpha \mathrm{S}$ to phospholipids (Choi et al. 2004; Jo et al. 2002; Perrin et al. 2000). It was suggested that the mechanism of toxicity in PD involves direct, disruptive interactions between $\alpha \mathrm{S}$ and lipid bilayers involving an interplay between growth of $\alpha \mathrm{S}$ aggregates and lipid extraction (Reynolds et al. 
2011). $\alpha$ S has also been shown to bind specifically to mitochondria, which can lead to disruption of their function (Nakamura et al. 2008).

Because of the potential relevance to both functional and pathological roles of $\alpha \mathrm{S}$, further characterization of interactions between $\alpha \mathrm{S}$ and lipid membranes is of great importance. There exists a significant body of work aimed at understanding the nature of interactions between $\alpha \mathrm{S}$ and lipid bilayers but it has proven difficult to characterize the membrane-bound state and the role of membranes on $\alpha \mathrm{S}$ aggregation. This challenge is directly related to the difficulty in isolating the membrane-bound protein from brain samples. In vitro studies have also not yet provided a clear mechanism for $\alpha \mathrm{S}$ aggregation in the presence of lipids in part due to variability of protein-starting sample and variety of conditions used in kinetic studies of the conversion of monomeric $\alpha \mathrm{S}$ into amyloid fibrils (Cole et al. 2002; Comellas et al. 2012; Fink, 2006; Galvagnion et al. 2015, 2016; Grey et al. 2011; Jo et al. 2000; Lee et al. 2002; Martinez et al. 2007; Zhu \& Fink, 2003). Here we present a biophysical analysis of $\alpha \mathrm{S}$-lipid interactions that unravels a role for the lipid head-group chemistry in both $\alpha \mathrm{S}$ binding and amyloid formation. Our experiments led us to the unexpected discovery of a hidden pathway involving oligomeric $\alpha \mathrm{S}$ species that, when bound to membranes, acted as templates for linear growth of thin $\alpha \mathrm{S}$ amyloid fibrils.

\section{Materials and methods}

\subsection{Materials}

DOPS (1,2-dioleoyl-sn-glycero-3-phospho-L-serine, sodium salt) and DOPG (1,2-dioleoyl-sn-glycero-3-phospho(1'-rac-glycerol), sodium salt) chloroform solutions were purchased from Avanti Polar Lipids (Alabaster, USA). Sodium phosphate monobasic $\left(\mathrm{NaH}_{2} \mathrm{PO}_{4} ; \geqslant 99.0 \%\right)$, sodium phosphate dibasic $\left(\mathrm{Na}_{2} \mathrm{HPO}_{4} ; \geqslant 99.0 \%\right)$ and thioflavin $\mathrm{T}$ UltraPure Grade (ThT) $(\geqslant 95 \%)$ were purchased from Sigma-Aldrich (Stockholm, Sweden).

\subsection{Protein and lipid vesicle preparation}

$\alpha \mathrm{S}$ was expressed and purified as described previously (Chorell et al. 2015). The protein was stored in a lyophilized form at $-80{ }^{\circ} \mathrm{C}$. Monomeric $\alpha \mathrm{S}$ was purified from the lyophilized powder dissolved in $8 \mathrm{M}$ urea and $20 \mathrm{mM}$ ethylene diamine tetra-acetic acid by size exclusion chromatography (SEC) on a Superdex 75 column (GE Healthcare, Uppsala, Sweden) into $20 \mathrm{mM}$ phosphate buffer, $\mathrm{pH}$ 6.5. Aggregation kinetic studies were also performed with samples of lyophilized protein dissolved directly in $20 \mathrm{mM}$ phosphate buffer, $\mathrm{pH} 6.5$, followed by filtration through $0.2 \mu \mathrm{m}$ syringe filters. These samples (found to contain both monomers and oligomers) consisted of only full-length $\alpha \mathrm{S}$ (no fragments) as assessed by SDS-PAGE. The protein concentration was determined spectrophotometrically using a molar extinction coefficient of $5960 \mathrm{M}^{-1} \mathrm{~cm}^{-1}$ at $280 \mathrm{~nm}$. Lipid vesicles were prepared by the lipid film hydration method. Appropriate volumes of chloroform solution of the lipid (DOPS or DOPG) were transferred to round bottom flask and the organic solvent was removed by rotary evaporation. The resultant film was further dried under vacuum for at least $3 \mathrm{~h}$ and then hydrated with $20 \mathrm{mM}$ phosphate buffer, $\mathrm{pH}$ 6.5. The liposome suspensions were extruded through polycarbonate filters with pore diameters of $100 \mathrm{~nm}$ using Avestin LiposoFast-Basic extruder. The size of the liposomes was measured by dynamic light scattering using a Zetasizer Nano ZS instrument (Malvern Instruments Ltd., Worcestershire, UK).

\subsection{Circular dichroism (CD) spectroscopy}

Far-UV CD spectra of $5 \mu \mathrm{M} \alpha \mathrm{S}$ in the presence of increasing concentrations of liposomes in $20 \mathrm{mM}$ phosphate buffer, $\mathrm{pH}$ $6 \cdot 5$, were recorded at $37^{\circ} \mathrm{C}$ on a Chirascan (Applied Photophysics, Leatherhead, UK) equipped with a Peltier temperature control unit. CD spectra between 250 and $200 \mathrm{~nm}$ were obtained using quartz cuvettes with path lengths of $1 \mathrm{~mm}$ and the following parameters: a bandwidth of $1 \mathrm{~nm}$, a step size of $1 \mathrm{~nm}$, a time per point of $1 \mathrm{~s}$ and averaging three individual spectra. The CD signal of the buffer and liposomes was recorded and subtracted from the CD signal of the protein.

\section{4. $C D$ data analysis}

CD titration curves were fitted using one-step binding model (Galvagnion et al. 2015): $F+\operatorname{Lipid}_{L} \leftrightarrows B$ (Lipid) $)_{L}$, where $F$ and $B$ represent $\alpha \mathrm{S}$-free in solution and bound to the vesicles, respectively, and $L$ is the number of lipid molecules interacting with one molecule of $\alpha \mathrm{S}$. Then:

$K_{D}=\frac{[F]\left[\text { Lipid }_{L}\right]}{\left[B(\text { Lipid })_{L}\right]}$

$[\alpha \mathrm{S}]=[F]+[B]$

$[$ Lipid $]=L\left(\left[\right.\right.$ Lipid $\left.\left._{L}\right]+\left[B(\text { Lipid })_{L}\right]\right)$

Detected CD signal can be expressed as a sum of contributions from $\alpha \mathrm{S}$ bound to the vesicles $\left(x_{B}=[B] /[\alpha \mathrm{S}]\right)$ and $\alpha \mathrm{S}$ free in solution $\left(x_{F}=[F] /[\alpha \mathrm{S}]\right)$ :

$x_{B}+x_{F}=1$

$\mathrm{CD}=x_{B} \mathrm{CD}_{B}+x_{F} \mathrm{CD}_{F}$

where $\mathrm{CD}_{B}$ and $\mathrm{CD}_{F}$ are the $\mathrm{CD}$ signals of the $\alpha \mathrm{S}$ bound and free states, respectively.

From Eqs. (4) and (5):

$x_{B}=\frac{\mathrm{CD}-\mathrm{CD}_{F}}{\mathrm{CD}_{B}-\mathrm{CD}_{F}}$

And from Eqs. (1)-(4): 
$x_{B}=\frac{\left([\alpha \mathrm{S}]+\frac{[\text { Lipid }]}{L}+K_{D}\right)-\sqrt{\left([\alpha \mathrm{S}]+\frac{[\text { Lipid }]}{L}+K_{D}\right)^{2}-\frac{4[\alpha \mathrm{S}][\text { Lipid }]}{L}}}{2[\alpha \mathrm{S}]}$

Matlab software package was used to fit CD titration curves using Eqs. (6) and (7).

\subsection{Aggregation kinetics}

$\alpha \mathrm{S}$ purified by SEC just before incubation or $\alpha \mathrm{S}$ dissolved directly in buffer was incubated at $37^{\circ} \mathrm{C}$ in $20 \mathrm{mM}$ phosphate buffer, $\mathrm{pH} 6 \cdot 5$, in the presence of $20 \mu \mathrm{M}$ thioflavin $\mathrm{T}$ (ThT) and different concentrations of DOPG and DOPS liposomes. The samples $(60 \mu \mathrm{l}$ per well) were incubated in non-binding polystyrene 96-well half-area plates with clear bottom (Corning Life Sciences, Tewksbury, USA) ThT fluorescence signal was monitored using a microplate reader (FLUOstar Optima, BMG Labtech, Ortenberg, Germany). The fluorescence (excitation wavelength $440 \mathrm{~nm}$, emission wavelength $480 \mathrm{~nm}$ ) was measured at every 20 min during the incubation and the plates were agitated for $5 \mathrm{~min}$ before each measurement to assure proper mixing of the samples. In the absence of liposomes, aggregation of $\alpha \mathrm{S}$ does not occur within the timeframe of our experiments $(100 \mathrm{~h})$.

\subsection{Atomic force microscopy (AFM)}

For AFM imaging, samples were diluted with Milli-Q water (10-20 times) and deposited on freshly cleaved mica. After $10 \mathrm{~min}$, the mica was rinsed with Milli-Q water and dried under a gentle nitrogen stream. Images were recorded in intermittent contact mode in air using an NTEGRA Prima setup (NT-MDT Spectrum Instruments, Moscow, Russia), a gold-coated single-crystal silicon cantilever (NT-MDT, NSG01, spring constant of $\sim 5 \cdot 1 \mathrm{~N} \mathrm{~m}^{-1}$ ) and a resonance frequency of $\sim 180 \mathrm{kHz} .512$ pixel images were acquired with $0.5 \mathrm{~Hz}$ scan rate. Images were analyzed using the WSxM 5.0 software (Horcas et al. 2007).

\section{Results}

\subsection{Binding of $\alpha \mathrm{S}$ to anionic lipid vesicles is modulated by lipid head-group chemistry}

We investigated the binding of monomeric $\alpha \mathrm{S}$ to lipid vesicles composed of DOPS or DOPG lipids by far-UV CD spectroscopy. Titration of large unilamellar liposomes (LUVs) to $\alpha \mathrm{S}$ induced a change from unordered to alphahelix structure in the protein, as indicated by characteristic negative bands at 208 and $222 \mathrm{~nm}$ in the CD spectrum (Fig. 1a). The CD signal at $222 \mathrm{~nm}$ of $\alpha \mathrm{S}$ scales almost linearly with increasing lipid concentration until saturation is reached (Fig. $1 b$ ) and the data can be well described by a one-step binding model. Fitting the binding curves with this model, we estimated the $\alpha \mathrm{S}$-lipid binding stoichiometry
$L$ (how many lipid molecules per one $\alpha \mathrm{S}$ molecule) and the apparent lipid-protein dissociation constant $K_{\mathrm{d}}$. For both types of lipid vesicles, the $\alpha \mathrm{S}$ dissociation constant was $\sim 0 \cdot 1 \mu \mathrm{M}(0 \cdot 10 \pm 0.08 \mu \mathrm{M}$ for DOPG and $0 \cdot 14 \pm 0 \cdot 12 \mu \mathrm{M}$ for DOPS), while the binding stoichiometry $L$ was approximately four times higher for DOPS compared with DOPG vesicles ( 83 versus 21 , respectively, lipids $/ \alpha \mathrm{S}$ ). This result demonstrates that the binding of $\alpha \mathrm{S}$ to negatively charged lipid vesicles is not solely based on electrostatic forces but must in part be defined also by interactions between the hydrophobic face of the amphipathic helix and the membrane interior, which are affected by properties such as surface chemistry and/or local structure of the lipid bilayer (Perrin et al. 2000).

\subsection{Amyloid formation of $\alpha S$ is differentially triggered by the two kinds of anionic lipid vesicles}

Our CD results showed different stoichiometry $L$ of $\alpha \mathrm{S}$ for DOPG and DOPS liposomes. To assess the importance of this for $\alpha \mathrm{S}$ amyloid formation in the presence of negatively charged vesicles, we exploited the typical ThT assay that utilizes the increase in fluorescence quantum efficiency of ThT when bound to amyloid fibrils (Groenning, 2010; LeVine, 1993). We chose a fixed concentration of $\alpha \mathrm{S}$ (70 $\mu \mathrm{M})$ and selected the concentrations of lipids according to the $\mathrm{CD}$ titration curves in order to create conditions at which $\alpha \mathrm{S}$ populates both the free in solution and bound to the vesicle states. In effective terms, this means similar alphahelix content of $\alpha \mathrm{S}$ but different lipid concentrations of DOPG and DOPS. We also tested saturating conditions at which essentially all $\alpha \mathrm{S}$ molecules are bound to the vesicles.

$\alpha \mathrm{S}(70 \mu \mathrm{M})$ incubated at $37^{\circ} \mathrm{C}$ for $100 \mathrm{~h}$ did not show an increase in ThT fluorescence, indicating the absence of amyloid fibrils detectable by ThT (Fig. 2). AFM confirmed the lack of amyloid fibrils at this condition. In contrast, the presence of negatively charged DOPG vesicles at lipid/protein molar ratios of $2 \cdot 1$ ( $10 \% \alpha \mathrm{S}$ bound to vesicles), $4 \cdot 2$ (20\% $\alpha \mathrm{S}$ bound) and $11.2(55 \% \alpha \mathrm{S}$ bound) triggered the formation of amyloid fibrils by $\alpha \mathrm{S}$ (Figs $2 a$ and $2 c$ ). At higher DOPG/ $\alpha \mathrm{S}$ molar ratios $(\geqslant 22 \cdot 4)$, where all $\alpha \mathrm{S}$ were bound to the vesicles, no increase in ThT fluorescence was observed. DOPS vesicles also promoted aggregation of $\alpha \mathrm{S}$ but with different features. At a DOPS $/ \alpha \mathrm{S}$ ratio of $10 \cdot 5$ (13\% $\alpha \mathrm{S}$ bound), protein aggregation was detected, but at higher ratios of DOPS/ $\alpha$ S (i.e., 21 and 56) no ThT fluorescence was observed albeit, according to the CD titration, both free and bound $\alpha \mathrm{S}$ states should be present (Figs $2 b$ and $2 d$ ). AFM imaging of end point samples (after $100 \mathrm{~h}$ ) indicated that in the plateau region of ThT fluorescence, the fibrils 

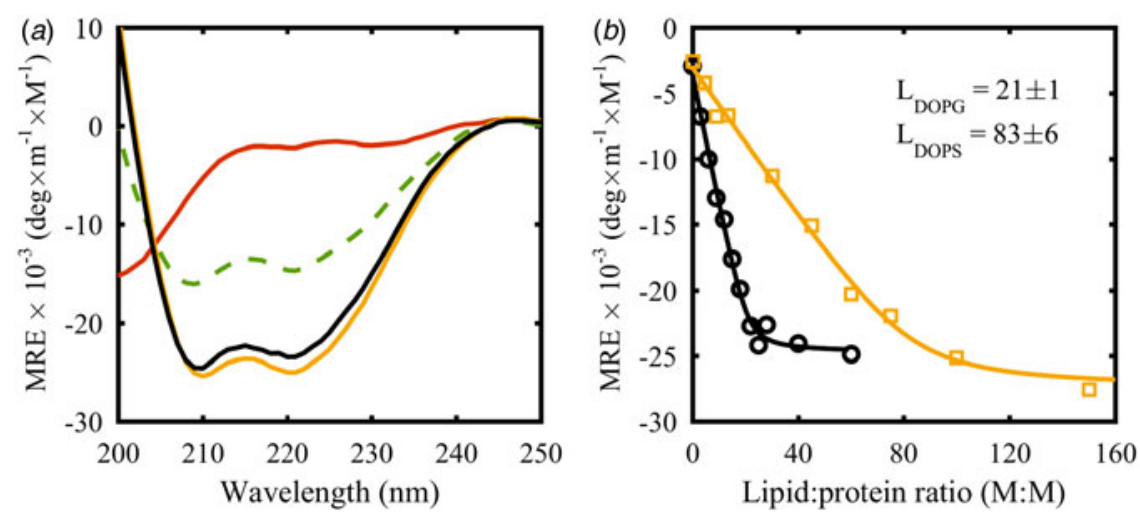

Fig. 1. Secondary structure of $\alpha \mathrm{S}$ in the presence of lipid vesicles. (a) CD spectra of $5 \mu \mathrm{M} \alpha \mathrm{S}$ alone (red) and $5 \mu \mathrm{M} \alpha \mathrm{S}$ in the presence of $200 \mu \mathrm{M}$ of DOPG (black) and $200 \mu \mathrm{M}$ (dashed green) and $530 \mu \mathrm{M}$ (yellow) of DOPS. (b) Mean residue ellipticity at $222 \mathrm{~nm}$ upon titration of DOPG (black, circles) and DOPS (yellow, squares) vesicles into $5 \mu \mathrm{M} \alpha \mathrm{S}$ solution; the experimental data are shown as symbols and a one-step binding model fit is shown as solid lines.
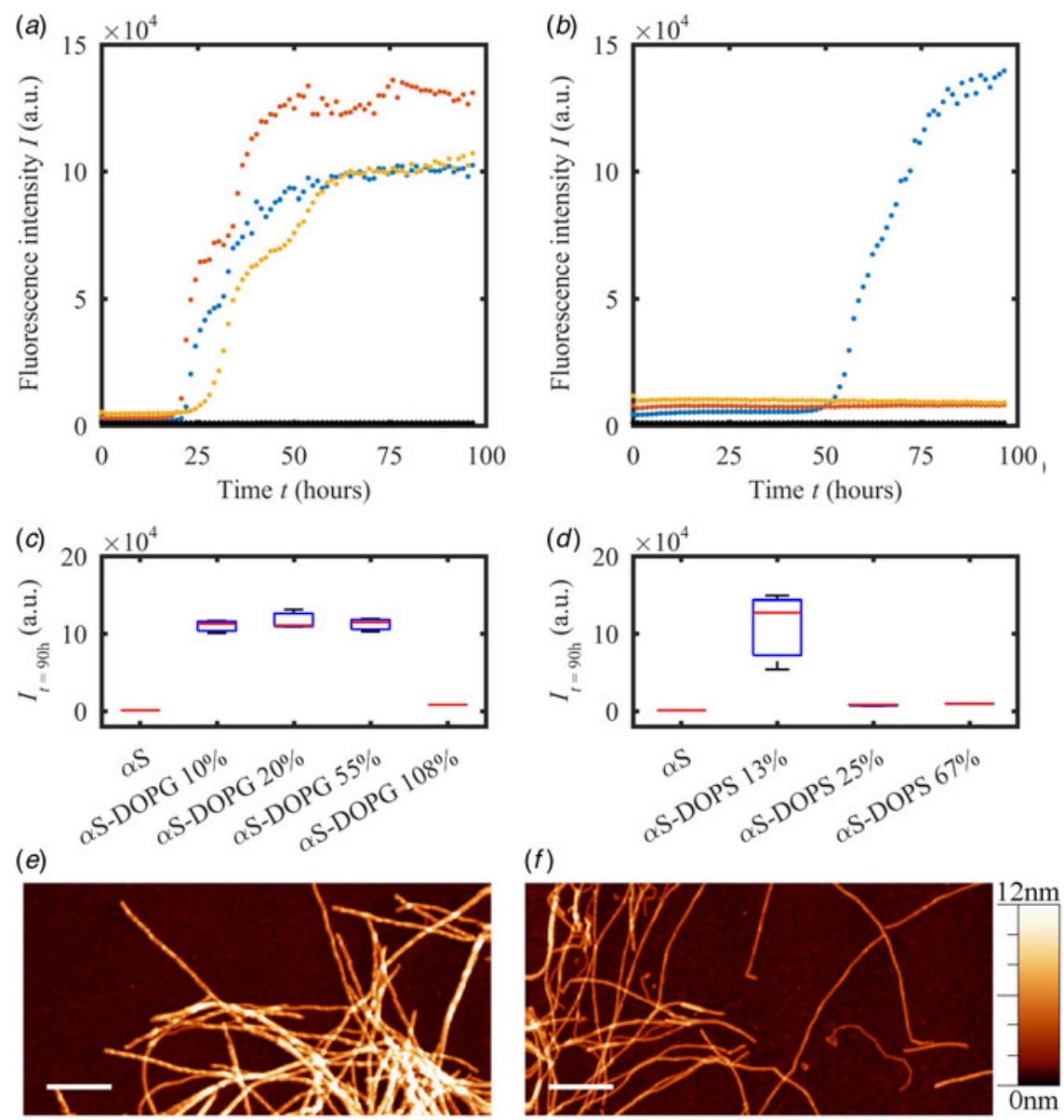

Fig. 2. Aggregation of $\alpha \mathrm{S}$ in the presence of negatively charged vesicles. ThT fluorescence of $\alpha \mathrm{S}$ alone (black) $(a, b)$ and of $\alpha \mathrm{S}$ incubated in the presence of $150 \mu \mathrm{M}(10 \% \alpha \mathrm{S}$ bound, blue), $300 \mu \mathrm{M}(20 \%$, red) and $790 \mu \mathrm{M}$ (55\%, yellow) of DOPG $(a)$ or in the presence of 735 $\mu \mathrm{M}(13 \%$, blue), $1470 \mu \mathrm{M}(25 \%$, red) and $3920 \mu \mathrm{M}(67 \%$, yellow) of DOPS $(b)$. Boxplots comparing ThT intensity at plateau $(t=90 \mathrm{~h})$ of $\alpha \mathrm{S}$ incubated in the presence of DOPG vesicles $(c)$ and DOPS vesicles $(d)$. AFM images of $\alpha \mathrm{S}$ amyloid fibrils at the end point of the aggregation experiment after incubation of monomeric $\alpha \mathrm{S}$ in the presence of $300 \mu \mathrm{M}$ DOPG $(e)$ and $735 \mu \mathrm{M}$ DOPS $(f)$ vesicles. Scale bars $500 \mathrm{~nm}$; height color-scale is shown on the right. 
formed in the presence of both types of negatively charged vesicles were heterogeneous, with some fibers of dimensions of 7-9 $\mathrm{nm}$ in height as well as some with dimensions $<5 \mathrm{~nm}$ in height (Figs $2 e$ and 2f). For comparison, these amyloid fiber properties are in agreement with those of $\alpha \mathrm{S}$ amyloids formed in the absence of vesicles but in the presence of a small glass bead and agitation to speed up the reaction (Fig. S1).

\section{3. $\alpha$ S oligomer 'contamination' dramatically alters $\alpha S$ aggregation in the presence of negatively charged vesicles}

In the above experiments, stock lyophilized $\alpha \mathrm{S}$ was dissolved and purified by SEC prior to use as a standard step to always assure monomeric starting material. Indeed, SEC analysis of lyophilized $\alpha \mathrm{S}$ samples showed the presence of protein species with a larger apparent size, indicative of an assembled and oligomeric fraction (Fig. S2). Moreover, AFM analysis demonstrated the presence of spherical structures with heights in the range of $1-3 \mathrm{~nm}$ in the lyophilized $\alpha \mathrm{S}$ sample (Fig. S2). Based on the SEC analysis, the oligomer fraction corresponds to approximately $5 \%$ of total protein and the oligomer size appears to be about $80 \mathrm{kDa}$ (Fig. S2). The oligomers appeared stable as they could not be dissociated by $8 \mathrm{M}$ urea (Fig. S2). As expected for a sample containing mostly monomers in mixture with a small fraction of oligomers, CD titrations curves with negatively charged vesicles using this $\alpha \mathrm{S}$ source matched the data collected for monomer-only $\alpha \mathrm{S}$ (Fig. S3, cf. Fig. 1).

Lyophilization has been reported to induce the formation of $\alpha \mathrm{S}$ oligomers and it has been proposed that these species may affect $\alpha \mathrm{S}$ aggregation (Fredenburg et al. 2007; Lashuel et al. 2002; Volles \& Lansbury, 2002). Therefore, we also investigated the aggregation kinetics of the heterogeneous $\alpha \mathrm{S}$ preparation (i.e., lyophilized $\alpha \mathrm{S}$ dissolved without further purification) in the presence of negatively charged vesicles. The ThT signal of lyophilized $\alpha \mathrm{S}$ reconstituted in buffer without vesicles did not change within $100 \mathrm{~h}$ at aggregation conditions, indicating no amyloid formation and, importantly, is the same result as that for the monomer-only $\alpha \mathrm{S}$ sample in the absence of vesicles (Figs $3 a$ and $3 b$ ).

In contrast, for this $\alpha \mathrm{S}$ sample, the ThT signal increased almost linearly with time without lag time in the presence of DOPG LUVs at lipid/protein ratios of $2 \cdot 1,4 \cdot 2,11 \cdot 2$ and DOPS/protein ratios of $10 \cdot 5$ (Figs $3 a$ and $3 b$ ). The amplitudes of these ThT changes were however very low, but nonetheless clearly distinct from the flat ThT curves for $\alpha \mathrm{S}$ without vesicles. AFM analysis revealed that thin amyloid fibrils, 3-4 $\mathrm{nm}$ in height, were present in these samples after the reactions (Figs $3 c$ and $3 d$ ). Thus, if a small fraction of oligomers is present along with $\alpha \mathrm{S}$ monomers, together with negatively charged vesicles, elongation of a small number of fibrils takes place, most likely with the pre-formed 'contaminating' oligomers as starting nuclei. At the same time, and most surprisingly, the typical cooperative aggregation seen for the monomer-only $\alpha \mathrm{S}$ samples in the presence of vesicles (Fig. 2) is absent.

\section{Discussion}

The binding of $\alpha \mathrm{S}$ to lipid membranes is described to depend on numerous factors such as solution conditions, chemical properties of the lipids, lipid bilayer phase state and membrane curvature (Galvagnion et al. 2016; Middleton \& Rhoades, 2010; Ouberai et al. 2013; Shvadchak et al. 2011a, b). Under the experimental conditions of this study, induction of the same amount of alpha-helical content in $\alpha \mathrm{S}$ required four times higher concentration of DOPS than DOPG vesicles. The area per lipid molecule of DOPS (65.3 $\AA^{2}$ (Petrache et al. 2004)) is almost $10 \%$ smaller than that of DOPG (70.8 $\AA^{2}$ (Pan et al. 2012)), indicating that attractive interactions between PS head-group are stronger than between PG head-group. Stronger attractive interactions will result in higher molecular order in the polar head-group region of DOPS relative to DOPG lipid layers (Lindblom et al. 1991) and increased exposure of hydrophobic parts of DOPG relative to DOPS lipid bilayers. It has been previously described that $\alpha \mathrm{S}$ binds with higher affinity to model membranes with defects, indicating that lipid packing strongly affects $\alpha \mathrm{S}$-membrane interactions (Nuscher et al. 2004; Ouberai et al. 2013; Shvadchak et al. 2011a). Thus, DOPG may expose more hydrophobic areas and $\alpha \mathrm{S}$ may insert deeper into the DOPG membrane than the DOPS membrane. This will increase the effective area of binding, since when the bilayer expands, the effective surface area per lipid will increase. This reasoning may explain the lower number of lipid molecules per $\alpha \mathrm{S}$ molecule for DOPG compared with DOPS. Different reported affinities of $\alpha \mathrm{S}$ for negatively charged head-group, going beyond the total charge, also emphasize specificity of $\alpha \mathrm{S}$ among acidic phospholipids (Nakamura et al. 2008; Rhoades et al. 2006).

$\mathrm{CD}$ of $\alpha \mathrm{S}$ binding to anionic lipid vesicles shows a transition from mostly disordered to largely alpha-helical conformation of $\alpha \mathrm{S}$. At an excess of lipids, most of $\alpha \mathrm{S}$ monomers are bound to the vesicles. We observed a maximum value of mean residue ellipticity (MRE) at $222 \mathrm{~nm}$ of $-25 \times 10^{3}$ and $-27 \times 10^{3} \operatorname{deg} \mathrm{m}^{-1} \mathrm{M}^{-1}$ for $\alpha \mathrm{S}$ bound to the DOPG and DOPS vesicles, respectively. Using the MRE values and assuming that all $\alpha \mathrm{S}$ molecules are bound to the vesicles, we estimate that $68-74 \%$ of the protein is in alphahelical structure (Scholtz et al. 1991), which corresponds to $\sim 100$ out of the 140 residues of $\alpha \mathrm{S}$. This result agrees with structural studies that have shown that the first 100 $\mathrm{N}$-terminal residues of $\alpha \mathrm{S}$ interact with lipid vesicles (Bodner et al. 2009, 2010). The number of $\alpha \mathrm{S}$ residues bound to the vesicles can be estimated by assuming that the dimensions of the alpha-helix are $\sim 0.13 \mathrm{~nm}$ per residue 

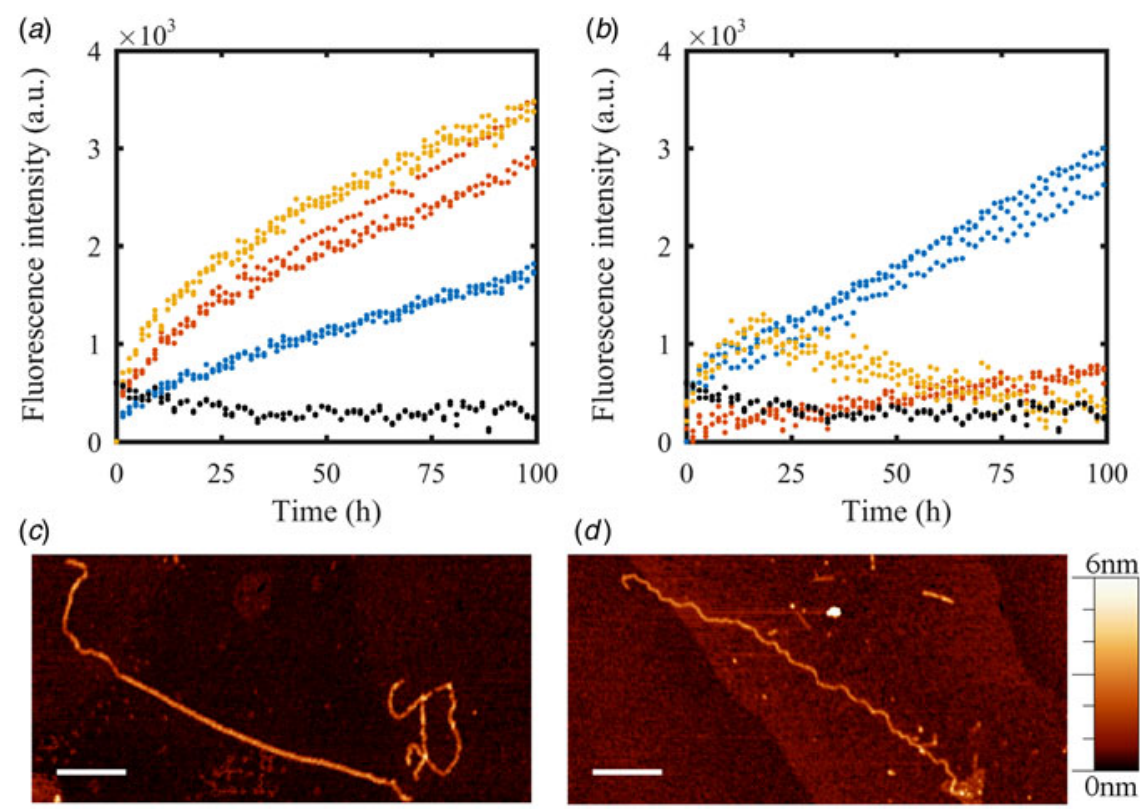

$(d)$

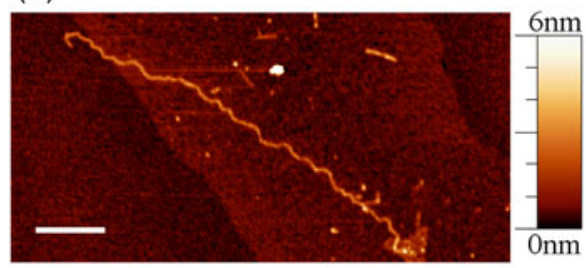

Fig. 3. Aggregation of $\alpha \mathrm{S}$, consisting of monomers and a small fraction of oligomers, in the presence of negatively charged vesicles. ThT fluorescence of $\alpha \mathrm{S}$ alone (black) $(a, b)$ and of $\alpha \mathrm{S}$ incubated in the presence of $150 \mu \mathrm{M}$ (blue), $300 \mu \mathrm{M}$ (red), $790 \mu \mathrm{M}$ (yellow) of DOPG vesicles $(a)$ or in the presence of $735 \mu \mathrm{M}$ (blue), $1470 \mu \mathrm{M}$ (red) and $3920 \mu \mathrm{M}$ (yellow) of DOPS vesicles $(b)$. We note that the ThT intensity in these graphs are approximately 20-fold lower than in Figs $2 a$ and $2 b$. AFM images of $\alpha \mathrm{S}$ amyloid fibrils at the end point of the aggregation experiment after incubation in the presence of $300 \mu \mathrm{M}$ DOPG (c) and $735 \mu \mathrm{M}$ DOPS (d) vesicles. Scale bars $500 \mathrm{~nm}$; height color-scale is shown on the right.

in length (Lee et al. 2004) and $1 \mathrm{~nm}$ in width in combination with the lipid-to-protein ratio at saturation determined here of 21 (lipid area of $7.5 \mathrm{~nm}^{2}$ ) for DOPG vesicles and 83 (lipid area of $27 \mathrm{~nm}^{2}$ ) for DOPS. We arrive at the result that only about 58 residues of each $\alpha \mathrm{S}$ can be accommodated on DOPG vesicles at saturation, whereas on DOPS surfaces the available area per $\alpha \mathrm{S}$ monomer corresponds to that of 200 residues in alpha-helical conformation.

This simple analysis may suggest that $\alpha \mathrm{S}$ induces a rearrangement of the DOPG bilayer resulting in lateral expansion such that accommodation of $100 \alpha \mathrm{S}$ residues per molecule is possible. In accord, it has been proposed that $\alpha \mathrm{S}$ binding to lipid bilayers can involve insertion of helical segments in the head-group region resulting in lateral expansion; importantly, this effect was highly dependent on the degree of order in the membrane (Ouberai et al. 2013). Another possibility is that part of the $\alpha \mathrm{S}$ helix is protruding from the membrane surface of the DOPG vesicles. It was previously reported that binding of $\alpha \mathrm{S}$ to PS-containing vesicles requires all residues $1-102$, whereas the binding to phosphatidic acid containing vesicles can be mediated by just one of the sequence segments $1-42,43-56$ or $56-102$ (Perrin et al. 2000).

We observed that DOPG and DOPS vesicles modulate differently amyloid formation of monomeric $\alpha \mathrm{S}$. At lipid/protein ratios high enough to have all $\alpha \mathrm{S}$ molecules bound to the vesicles, the protein did not aggregate within the time frame of our experiments $(100 \mathrm{~h})$. However, for both vesicle types, when free monomers are present in solution, fibril formation took place and the process showed an initial lag phase, which is attributed to a nucleation-dependent mechanism (Fink, 2006; Wood et al. 1999). As the nucleation of $\alpha \mathrm{S}$ occurred faster in the presence of DOPG vesicles than in their absence, we can assume that it is the lipid-bound $\alpha \mathrm{S}$ fraction that forms the initial nuclei. Probably, the lipid environment increases the local concentration of $\alpha \mathrm{S}$, promoting self-assembly of membrane-bound $\alpha \mathrm{S}$ molecules and consequently leading to the formation of nuclei on the bilayer surface. If we make the assumption that alphahelix content corresponds to bound $\alpha \mathrm{S}$, then DOPG vesicles induce amyloid formation of monomeric $\alpha \mathrm{S}$ as long as both bound and free protein states are present. In contrast, in the case of DOPS, aggregation of $\alpha \mathrm{S}$ occurred only for $13 \%$ of $\alpha \mathrm{S}$ bound to lipids and the lag phase with DOPS was longer than for $\alpha \mathrm{S}$ with DOPG at the same percentage of vesiclebound protein. Higher DOPS-bound fraction of $\alpha S$ than $13 \%$ resulted in the absence of any amyloid formation. Also when comparing the DOPS and DOPG results for similar absolute lipid concentrations, corresponding to lipid/protein ratio of 10.5 and 11.2 , respectively, the lag times of $\alpha \mathrm{S}$ amyloid formation are still much longer in the case of DOPS than DOPG. These data suggest that efficiency of $\alpha \mathrm{S}$ nucleation on vesicles is dependent on vesicle surface chemistry, dynamics and structure, which together define the $\alpha \mathrm{S}$ binding mode. It was previously suggested 
that $\alpha \mathrm{S}$ aggregation is promoted only by lipids with short saturated hydrocarbon chains (12 or 14 carbon chain) (Galvagnion et al. 2016). Our results here show that $\alpha \mathrm{S}$ aggregation can also be promoted by long unsaturated hydrocarbon chains (i.e., DOPS, DOPG; 18 carbon chain with one double bond) at some conditions. Based on previous studies, it is possible that $\alpha \mathrm{S}$ aggregation on vesicles involves extraction of lipids from the bilayer and partial protein-lipid co-aggregation (Hellstrand et al. 2013; Reynolds et al. 2011).

Unexpectedly, we found that $\alpha \mathrm{S}$ amyloid formation in the presence of vesicles changes dramatically when a small fraction of oligomers is present. The AFM data suggested the formation of a small fraction of amyloid fibrils that were thin (Fink, 2006; Khurana et al. 2003). These amyloid fibrils grew without lag phase implying that the pre-formed 'contaminating' oligomers were the source of nuclei. Notably, this process blocked the aggregation of the remaining monomers, which contrasts the result for monomers-only $\alpha \mathrm{S}$ samples in the presence of negatively charged vesicles. Since amyloid fibrils were absent from aggregation reactions of this $\alpha \mathrm{S}$ sample without vesicles, the 'contaminating' oligomers must depend on the vesicles for nucleation of amyloid formation. $\alpha \mathrm{S}$ oligomers are described to interact with negatively charged bilayers and may cause membrane disruption (Fredenburg et al. 2007; van Rooijen et al. 2009). The molecular details of oligomer-membrane interactions and the effect on surrounding monomeric species by those interactions are still unclear. If $\alpha \mathrm{S}$ interactions with lipid vesicles are cooperative, then even a few (or one) oligomers may alter the way many monomers arrange on the surface of the liposome. Notably, a study on $\alpha \mathrm{S}$ aggregation on supported lipid bilayers showed that monomeric $\alpha \mathrm{S}$ has a higher affinity for protein aggregates on the surface than for the lipid bilayer itself (Reynolds et al. 2011). Moreover, similar to our results here, the study showed that after the initial formation of the first aggregates, these grew with time but the formation of new $\alpha \mathrm{S}$ seeds occurs at much lower frequency.

Our findings point out the importance of careful assessment of membrane properties, and synergistic effects due to protein-lipid interactions, as well as both lipid vesicle and protein structural dynamics. Our study also highlights the importance of protein preparation procedures. The literature around $\alpha \mathrm{S}$ aggregation includes a wide variation of results and at least some of these may be explained by differences in protein starting material.

\subsection{Speculation box}

Based on this work, we speculate that consequences of $\alpha \mathrm{S}$ interactions with synaptic vesicles and membranes in vivo will depend on simultaneous interactions with other proteins that may modulate vesicle surface properties. It appears that binding of pre-formed oligomers to vesicles alters surface properties such that monomers are restricted from independent formation of amyloid seeds. Our results also highlight the question of what in vitro conditions are most relevant for the in vivo scenario that ultimately results in PD. Finally, we note that to gain real biological bearing of these in vitro findings, vesicles composed of mixed lipids mimicking those in neuronal cells should be investigated.

\section{Acknowledgements}

Funding is acknowledged from the Knut and Alice Wallenberg foundation, the Swedish Research Council, the Chalmers Foundation and the People Program (Marie Curie Actions) of the European Union's Seventh Framework Program FP7/2007-2013/under REA Grant Agreement No. 607842 (to JK).

\section{Conflict of interest}

None.

\section{Supplementary material}

The supplementary material for this article can be found at https://doi.org/10.1017/S0033583517000026

\section{References}

Bodner, C. R., Dobson, C.M. \& Bax, A. (2009). Multiple tight phospholipid-binding modes of alpha-synuclein revealed by solution NMR spectroscopy. Journal of Molecular Biology 390, 775-790.

Bodner, C. R., Maltsev, A. S., Dobson, C. M. \& Bax, A. (2010). Differential phospholipid binding of alpha-synuclein variants implicated in Parkinson's disease revealed by solution NMR spectroscopy. Biochemistry 49, 862-871.

Choi, W., Zibaee, S., Jakes, R., Serpell, L. C., Davletov, B., Crowther, R. A. \& Goedert, M. (2004). Mutation E46 K increases phospholipid binding and assembly into filaments of human alpha-synuclein. FEBS Letters 576, 363-368.

Chorell, E., Andersson, E., Evans, M. L., Jain, N., Gotheson, A., Aden, J., Chapman, M.R., Almqvist, F. \& Wittung-Stafshede, P. (2015). Bacterial chaperones CsgE and CsgC differentially modulate human alpha-synuclein amyloid formation via transient contacts. PLoS ONE 10, e0140194.

Cole, N. B., Murphy, D. D., Grider, T., Rueter, S., Brasaemle, D. \& Nussbaum, R. L. (2002). Lipid droplet binding and oligomerization properties of the Parkinson's disease protein alphasynuclein. Journal of Biological Chemistry 277, 6344-6352.

Comellas, G., Lemkau, L. R., Zhou, D. H., George, J. M. \& Rienstra, C. M. (2012). Structural intermediates during alpha-synuclein fibrillogenesis on phospholipid vesicles. Journal of the American Chemical Society 134, 5090-5099. 
Davidson, W. S., Jonas, A., Clayton, D. F. \& George, J. M. (1998). Stabilization of alpha-synuclein secondary structure upon binding to synthetic membranes. Journal of Biological Chemistry 273, 9443-9449.

Dev, K. K., Hofele, K., Barbieri, S., Buchman, V. L. \& van der Putten, H. (2003). Part II: alpha-synuclein and its molecular pathophysiological role in neurodegenerative disease. Neuropharmacology 45, 14-44.

Eliezer, D., Kutluay, E., Bussell, Jr., R. \& Browne, G. (2001). Conformational properties of alpha-synuclein in its free and lipid-associated states. Journal of Molecular Biology 307, 10611073.

FINK, A.L. (2006). The aggregation and fibrillation of alphasynuclein. Accounts of Chemical Research 39, 628-634.

Fredenburg, R. A., Rospigliosi, C., Meray, R. K., Kessler, J. C., Lashuel, H. A., Eliezer, D. \& Lansbury, P. T. (2007). The impact of the E46 K mutation on the properties of alpha-synuclein in its monomeric and oligomeric states. Biochemistry 46, 7107-7118.

Fusco, G., De Simone, A., Gopinath, T., Vostrikov, V., Vendruscolo, M., Dobson, C. M. \& Veglia, G. (2014). Direct observation of the three regions in alpha-synuclein that determine its membranebound behaviour. Nature Communications 5, 3827.

Galvagnion, C., Brown, J.W.P., Ouberai, M. M., Flagmeier, P., Vendruscolo, M., Buell, A. K., Sparr, E. \& Dobson, C. M. (2016). Chemical properties of lipids strongly affect the kinetics of the membrane-induced aggregation of alpha-synuclein. Proceedings of the National Academy of Sciences of the United States of America 113, 7065-7070.

Galvagnion, C., Buell, A. K., Meisl, G., Michaels, T. C. T., Vendruscolo, M., Knowles, T. P. J. \& Dobson, C. M. (2015). Lipid vesicles trigger alpha-synuclein aggregation by stimulating primary nucleation. Nature Chemical Biology 11, 229-U101.

Grey, M., Linse, S., Nilsson, H., Brundin, P. \& Sparr, E. (2011). Membrane interaction of alpha-synuclein in different aggregation states. Journal of Parkinson's Disease 1, 359-371.

Groenning, M. (2010). Binding mode of thioflavin $\mathrm{T}$ and other molecular probes in the context of amyloid fibrils-current status. Journal of Biological Chemistry 3, 1-18.

Hellstrand, E., Nowacka, A., Topgaard, D., Linse, S. \& Sparr, E. (2013). Membrane lipid co-aggregation with alpha-synuclein fibrils. PLOS ONE 8, e77235.

Horcas, I., Fernández, R., Gómez-Rodríguez, J. M., Colchero, J., Gómez-Herrero, J. \& Baro, A. M. (2007). WSXM: a software for scanning probe microscopy and a tool for nanotechnology. Review of Scientific Instruments 78, 013705.

Inai, A., Masliah, E., Yoshimoto, M., Ge, N., Flanagan, L., De Silva, H. A., Kittel, A. \& SAIтOH, T. (1995). The precursor protein of non-A beta component of Alzheimer's disease amyloid is a presynaptic protein of the central nervous system. Neuron 14, 467-475.

Jo, E. J., Fuller, N., Rand, R. P., St George-Hyslop, P. \& Fraser, P. E. (2002). Defective membrane interactions of familial Parkinson's disease mutant A30P alpha-synuclein. Journal of Molecular Biology 315, 799-807.

Jo, E. J., McLaurin, J., Yip, C. M., St George-Hyslop, P. \& Fraser, P.E. (2000). Alpha-synuclein membrane interactions and lipid specificity. Journal of Biological Chemistry 275, 34328-34334.

Khurana, R., Ionescu-Zanetti, C., Pope, M., Li, J., Nielson, L., Ramirez-Alvarado, M., Regan, L., Fink, A. L. \& Carter, S. A.
(2003). A general model for amyloid fibril assembly based on morphological studies using atomic force microscopy. Biophysical Journal 85, 1135-1144.

Lashuel, H. A., Petre, B. M., Wall, J., Simon, M., Nowak, R. J., Walz, T. \& Lansbury, P. T. (2002). Alpha-synuclein, especially the Parkinson's disease-associated mutants, forms pore-like annular and tubular protofibrils. Journal of Molecular Biology 322, 1089-1102.

Lassen, L. B., Reimer, L., Ferreira, N., Betzer, C. \& Jensen, P. H. (2016). Protein partners of alpha-synuclein in Health and Disease. Brain Pathology 26, 389-397.

Lee, H. J., Chol, C. \& Lee, S. J. (2002). Membrane-bound alphasynuclein has a high aggregation propensity and the ability to seed the aggregation of the cytosolic form. Journal of Biological Chemistry 277, 671-678.

Lee, J. C., Langen, R., Hummel, P. A., Gray, H. B. \& Winkler, J. R. (2004). Alpha-synuclein structures from fluorescence energytransfer kinetics: implications for the role of the protein in Parkinson's disease. Proceedings of the National Academy of Sciences of the United States of America 101, 16466-16471.

LeVINe, H. (1993). Thioflavine $\mathrm{T}$ interaction with synthetic Alzheimer's disease beta-amyloid peptides: detection of amyloid aggregation in solution. Protein Science 2, 404-410.

Lindblom, G., Rilfors, L., Hauksson, J. B., Brentel, I., Sjoelund, M. \& Bergenstahl, B. (1991). Effect of head-group structure and counterion condensation on phase equilibria in anionic phospholipid-water systems studied by deuterium, sodium-23, and phosphorus-31 NMR and x-ray diffraction. Biochemistry 30, 10938-10948.

Maroteaux, L., Campanelli, J.T. \& Scheller, R. H. (1988). Synuclein: a neuron-specific protein localized to the nucleus and presynaptic nerve terminal. The Journal of Neuroscience $\mathbf{8}$, 2804-2815.

Martinez, Z., Zhu, M., Han, S. B. \& Fink, A. L. (2007). GM1 specifically interacts with alpha-synuclein and inhibits fibrillation. Biochemistry 46, 1868-1877.

Middleton, E. R. \& RhoAdes, E. (2010). Effects of curvature and composition on alpha-synuclein binding to lipid vesicles. Biophysical Journal 99, 2279-2288.

Nakamura, K., Nemani, V. M., Wallender, E. K., Kaehlcke, K., OtT, M. \& EDWARDS, R. H. (2008). Optical reporters for the conformation of alpha-synuclein reveal a specific interaction with mitochondria. Journal of Neuroscience 28, 12305-12317.

Nuscher, B., Kamp, F., Mehnert, T., Odoy, S., Haass, C., Kahle, P. J. \& BEYER, K. (2004). Alpha-synuclein has a high affinity for packing defects in a bilayer membrane - a thermodynamics study. Journal of Biological Chemistry 279, 21966-21975.

Ouberai, M. M., Wang, J., Swann, M. J., Galvagnion, C., Guilliams, T., Dobson, C. M. \& Welland, M.E. (2013). Aalpha-synuclein senses lipid packing defects and induces lateral expansion of lipids leading to membrane remodeling. Journal of Biological Chemistry 288, 20883-20895.

Pan, J. J., Heberle, F. A., Tristram-Nagle, S., Szymanski, M., Koepfinger, M., Katsaras, J. \& KucerKa, N. (2012). Molecular structures of fluid phase phosphatidylglycerol bilayers as determined by small angle neutron and X-ray scattering. Biochimica et Biophysica Acta - Biomembranes 1818, 2135-2148.

Perrin, R. J., Woods, W. S., Clayton, D. F. \& George, J. M. (2000). Interaction of human alpha-synuclein and Parkinson's disease 
variants with phospholipids - structural analysis using sitedirected mutagenesis. Journal of Biological Chemistry 275, 34393-34398.

Petrache, H. I., Tristram-Nagle, S., Gawrisch, K., Harries, D., Parsegian, V. A. \& Nagle, J. F. (2004). Structure and fluctuations of charged phosphatidylserine bilayers in the absence of salt. Biophysical Journal 86, 1574-1586.

Polymeropoulos, M. H., Lavedan, C., Leroy, E., Ide, S. E., Dehejia, A., Dutra, A., Pike, B., Root, H., Rubenstein, J., Boyer, R., Stenroos, E. S., Chandrasekharappa, S., Athanassiadou, A., Papapetropoulos, T., Johnson, W. G., Lazzarini, A. M., Duvoisin, R. C., Di Iorio, G., Golbe, L. I. \& Nussbaum, R. L. (1997). Mutation in the alpha-synuclein gene identified in families with Parkinson's disease. Science 276, 2045-2047.

Reynolds, N. P., Soragni, A., Rabe, M., Verdes, D., Liverani, E., Handschin, S., Riek, R. \& Seeger, S. (2011). Mechanism of membrane interaction and disruption by alpha-synuclein. Journal of the American Chemical Society 133, 19366-19375.

Rhoades, E., Ramlall, T.F., WebB, W.W. \& Eliezer, D. (2006). Quantification of alpha-synuclein binding to lipid vesicles using fluorescence correlation spectroscopy. Biophysical Journal 90, 4692-4700.

Scholtz, J. M., Qian, H., York, E. J., Stewart, J. M. \& Baldwin, R. L. (1991). Parameters of helix-coil transition theory for alaninebased peptides of varying chain lengths in water. Biopolymers 31, 1463-1470.

Shvadchak, V. V., Falomir-Lockhart, L. J., Yushchenko, D. A. \& Jovin, T. M. (2011a). Specificity and kinetics of alpha-synuclein binding to model membranes determined with fluorescent excited state intramolecular proton transfer (ESIPT) probe Journal of Biological Chemistry 286, 13023-13032.

Shvadchak, V. V., Yushchenko, D. A., Pievo, R. \& Jovin, T. M. (2011b). The mode of alpha-synuclein binding to membranes depends on lipid composition and lipid to protein ratio. FEBS Letters 585, 3513-3519.

Spillantini, M. G., Schmidt, M. L., Lee, V. M., Trojanowski, J. Q., JAKes, R. \& GoEdert, M. (1997). Alpha-synuclein in Lewy bodies. Nature 388, 839-840.

UVERSKY, V. N. (2007). Neuropathology, biochemistry, and biophysics of alpha-synuclein aggregation. Journal of Neurochemistry 103, 17-37.

van Rooijen, B. D., Claessens, M. M. A.E. \& Subramaniam, V. (2009). Lipid bilayer disruption by oligomeric alpha-synuclein depends on bilayer charge and accessibility of the hydrophobic core. Biochimica et Biophysica Acta - Biomembranes 1788, 1271-1278.

Volles, M. J. \& LansburY, Jr., P. T. (2002). Vesicle permeabilization by protofibrillar alpha-synuclein is sensitive to Parkinson's disease-linked mutations and occurs by a pore-like mechanism. Biochemistry 41, 4595-4602.

Wood, S. J., Wypych, J., Steavenson, S., Louis, J. C., Citron, M. \& BIERE, A. L. (1999). Alpha-synuclein fibrillogenesis is nucleationdependent - implications for the pathogenesis of Parkinson's disease. Journal of Biological Chemistry 274, 19509-19512.

ZHU, M. \& FinK, A. L. (2003). Lipid binding inhibits alpha-synuclein fibril formation. Journal of Biological Chemistry 278, 1687316877. 